九州大学学術情報リポジトリ

Kyushu University Institutional Repository

\title{
Compositional distribution of laser-deposited films and rapid sequential pulsed laser deposition
}

Watanabe, Yukio

Mitsubishi Chemical Yokohama Research Center

Seo, Y.

Mitsubishi Chemical Yokohama Research Center

Tanamura, M.

Mitsubishi Chemical Yokohama Research Center

Asami, $\mathrm{H}$.

Mitsubishi Chemical Yokohama Research Center

他

http://hdl. hand le. net/2324/4493205

出版情報: Journal of Applied Physics. 78 (8), pp.5126-5135, 1995-10-15. American Institute of Physics

バージョン:

権利関係：๑1995 American Institute of Physics 


\section{Compositional distribution of laser- deposited films and rapid sequential pulsed laser deposition}

Cite as: Journal of Applied Physics 78, 5126 (1995); https://doi.org/10.1063/1.359744 Submitted: 07 March 1995 . Accepted: 29 June 1995. Published Online: 17 August 1998

Yukio Watanabe, Y. Seo, M. Tanamura, et al.

\section{ARTICLES YOU MAY BE INTERESTED IN}

Laser power dependence of particulate formation on pulse laser deposited films Journal of Applied Physics 78, 2029 (1995); https://doi.org/10.1063/1.360179

\section{Challenge us.}

What are your needs for periodic signal detection?

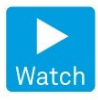

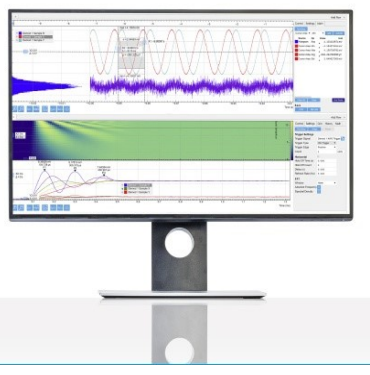

Zurich Instruments 


\title{
Compositional distribution of laser-deposited films and rapid sequential pulsed laser deposition
}

\author{
Yukio Watanabe, ${ }^{\text {a) }}$ Y. Seo, M. Tanamura, H. Asami, and Y. Matsumoto \\ Mitsubishi Chemical Yokohama Research Center, Yokohama, Japan 227
}

(Received 7 March 1995; accepted for publication 29 June 1995)

\begin{abstract}
Compositional distributions of films laser deposited in vacuo at energy densities $<1 \mathrm{~J} / \mathrm{cm}^{2}$ were found to be partly different from previous observations and theories. Analyzing them, we have inferred that evaporation processes at low energy densities contain decomposition of the target materials and evaporation of the decomposed materials. Based on these analyses, we have concluded that pulsed laser codeposition was one of best pulsed laser deposition methods. To realize this using one laser source, a modified version of pulsed-laser-deposition rapid-sequential-pulsed-laser deposition, is introduced. The dependence of $\mathrm{YBa}_{2} \mathrm{Cu}_{3} \mathrm{O}_{7}$ films properties on deposition conditions is discussed. Elimination of particulates is demonstrated and good electrical and crystallographic properties as well as suppression of precipitates were achieved in films having the correct stoichiometric composition. (C) 1995 American Institute of Physics.
\end{abstract}

\section{INTRODUCTION}

Pulsed laser deposition (PLD) ${ }^{1}$ is a versatile method to deposit ceramic thin films such as cuprate superconductor films, ${ }^{2,3}$ semiconductor films, ${ }^{4}$ and ferroelectric films. ${ }^{5}$ In case of high- $T_{c}$ superconducting films, excellent electrical properties such as a high $T_{c}$ and $J_{c}$, low microwave surface resistance, and good crystallinity as measured by narrow rocking curve widths have been reported. ${ }^{2,6}$ Furthermore, a local flatness and a layer-by-layer growth were observed by reflection high-energy electron diffraction (RHEED) oscillations. ${ }^{3}$ Despite all these advantages, a serious problem in PLD remains to be solved: particulate or boulder formation. This problem is not so serious when some target materials such as $\mathrm{SrTiO}_{3}$ (Refs. 7 and 8) or $\mathrm{BaTiO}_{3}$ (Ref. 9) are used; however, the problem is detrimental especially to multilayers. Careful studies of high- $T_{c}$ films have led to classification of particles into two groups: $:^{10,11}$ precipitates, which are also observed in films formed by the other methods, and particulates, which are unique to films grown by PLD.

There are other problems in a conventional PLD. A simple control of the film composition using a single target has been one of the primary merits of PLD technique; however, this is achieved only in a narrow range of gas pressure, target-substrate distance (T/S), and laser power density. Moreover, previous studies showed compositional change of target surface over time when laser irradiated at a low laser power density so that particulates could be suppressed. Additionally, the present results suggested that decomposition of target surface material during laser heating had occurred. We regarded the free choice of ambient gas and ambient gas pressure and the ability to supply excited adatoms as the most important properties of a PLD, but have discarded use of a single target to solve the above problems. Developing this approach, we have recently proposed a rapid sequential pulsed laser deposition (RSPLD). ${ }^{12}$ In this article we discuss the problems inherent to a conventional PLD first by show-

${ }^{2)}$ Present address: Department of Electrical Engineering, Kyushu Institute of Technology. ing nonuniform thickness distributions. Next, we introduce RSPLD as a method to resolve these problems and discuss the relation of in situ grown $\mathrm{YBa}_{2} \mathrm{Cu}_{3} \mathrm{O}_{7}(\mathrm{YBCO})$ film surface morphology with RSPLD conditions.

\section{EXPERIMENT}

Oxide targets were prepared through conventional sintering processes in air, and metal and alloy targets were made by arc melting. Targets were mounted on a rotating carousel. The carousel can rotate at a speed up to $600 \mathrm{rpm}$ with a positioning accuracy of $0.36^{\circ}$. An ArF laser was triggered as selected portions of specific targets were moved into the laser beam. The attenuator-controlled laser power could be adjusted to each target within $1 \mathrm{~ms}$ resolution. $\mathrm{A} \mathrm{MgO}(100)$ or a $\mathrm{SrTiO}_{3}(100)$ substrate was set at a distance of $80 \mathrm{~mm}$ from a target and the substrate temperature $T_{s}$ was varied between 600 and $650^{\circ} \mathrm{C}$ in RSPLD. Molecular oxygen pressure in the chamber was between 50 and $100 \mathrm{mTorr}$.

Macroscopic surface morphology was studied with an optical microscope and a scanning electron microscope (SEM). Microscopic roughness was measured by the grazing incidence $x$-ray reflectivity method. ${ }^{13}$ Average film compositions were analyzed by $\mathrm{x}$-ray fluorescent spectroscopy and inductively coupled plasma spectroscopy, and local compositional variations were studied by SEM equipped with energy-dispersive $\mathrm{x}$-ray spectroscopy (EDX).

\section{A. Basic characteristics of PLD}

\section{Particulate formation}

Figure 1(a) shows a SEM picture of a typical YBCO film by a conventional PLD, which exhibited zero resistance $\left(T_{c}\right)$ at $88 \mathrm{~K}$. A spherical particulate was visible in the picture, and its composition analyzed by electron probe microanalysis was $\mathrm{CuO}_{x}$. By using a low power density $\sim 1 \mathrm{~J} / \mathrm{cm}^{2}$, it was possible to reduce number of particulates down to about $10^{5} / 1000 \AA \mathrm{cm}^{2}$. In this case, however, their $T_{c}$ were not 


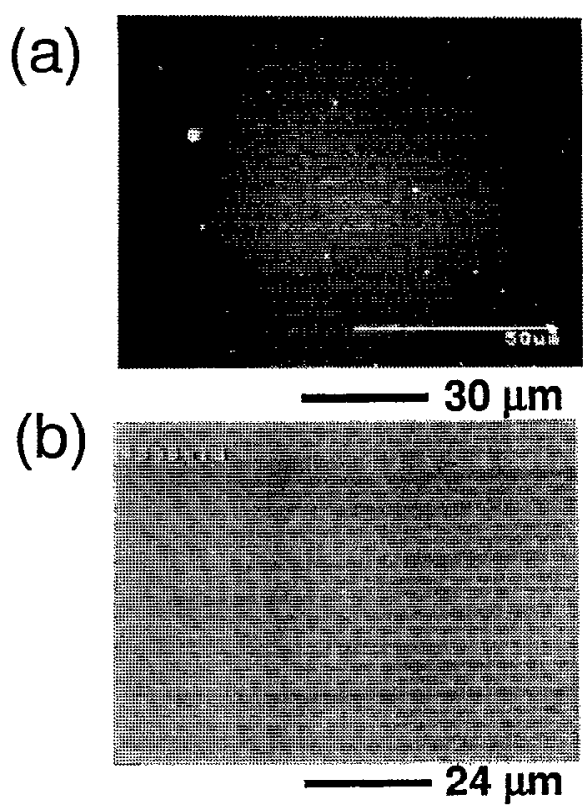

FIG. 1. SEM picture of typical surface morphology of films by conventional PLD: (a) A 600 -Â-thick YBCO film on $\mathrm{LaAlO}_{3}(001)$ and (b) a 800-Ä-thick $\left(\mathrm{La}, \mathrm{Sr}_{2}\right)_{2} \mathrm{CuO}_{4}$ film on $\mathrm{SrTiO}_{3}(001)$.

reproducible and varied between 70 and $88 \mathrm{~K}$. These particulate problems seem material dependent. For example, $\mathrm{SrTiO}_{3}$ and $\mathrm{BaTiO}_{3}$ films practically free of particulate were reported, ${ }^{7-9}$ and $(\mathrm{La}, \mathrm{Sr})_{2} \mathrm{CuO}_{4}$ films without particulates were obtained after optimization [Fig. 1(b)].

The observed $\mathrm{CuO}_{x}$ particulate may be interpreted as the precipitates; however, these particulates were observed also on the films deposited at room temperature. ${ }^{14}$ Moreover, $\mathrm{CuO}_{x}$ segregations were often found on the peripheral of the laser-irradjated area of YBCO targets. A possible origin of particulate having composition different from the target bulk composition as well as detailed study of the particulates was discussed elsewhere. ${ }^{14}$

\section{Angular distribution of deposited elements}

The irreproducibility in the particulate suppression is likely associated with change of target surface. Its effect can be seen also in compositional distribution on films.

Compositional distribution of deposited elements was studied by several authors. ${ }^{15,16}$ The results agreed well with the theories, ${ }^{17,18}$ which were based on a thermal heating process by laser and neglected collision of laser-ablated species with an ambient gas. However, most of the compositional distributions were measured using the films deposited at ambient gas pressure of 0.1 Torr or more, ${ }^{15,16}$ while we observed a drastic change of compositional distribution by an ambient gas. Therefore, we have reexamined it at an ambient gas pressure of $1 \times 10^{-5}$ Torr at room temperature (RT) so that a meaningful comparison with the theories could be made.

Figure 2(a) shows distribution of $\mathrm{Ba} / \mathrm{Cu}$ molar ratio of the films deposited at different laser fluences at R.T., using a fresh YBCO target in each run. Figure 3 shows the definition of the coordinate system in Fig. 2(a). In most of our experi- (a)

(b)
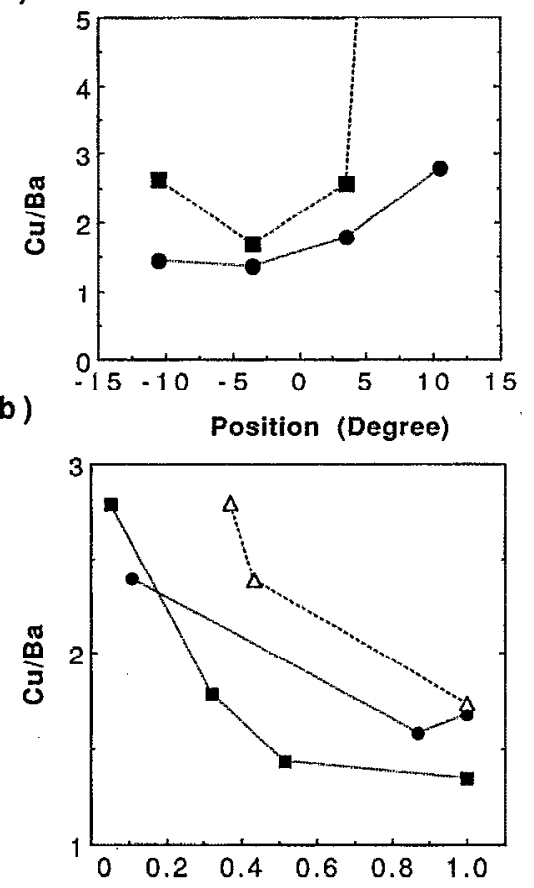

Ba Thickness Normalized by Peak Value

FIG. 2. (a) Distribution of $\mathrm{Ba} / \mathrm{Cu}$ molar ratio of the films deposited using YBCO targets at $0.85 \mathrm{~J} / \mathrm{cm}^{2}$ (solid line) and $0.25 \mathrm{~J} / \mathrm{cm}^{2}$ (dashed lined) (b) at R.T. and its different representation, where the abscissa is the total deposit amount. The solid lines and the dashed line correspond to the films deposited at 0.85 and at $0.25 \mathrm{~J} / \mathrm{cm}^{2}$, respectively. The symbols correspond to data of different runs.

ments the total molar deposit peaked at the angle of $-3^{\circ}$ to $-7^{\circ}$. This was probably due to the formation of microstructures, e.g., columnar structures, on the target surface during laser evaporation.

In Fig. 2(a) the $\mathrm{Cu} / \mathrm{Ba}$ ratio had the minimum at $-3^{\circ}$ where the $\mathrm{Ba}, \mathrm{Cu}$, and $\mathrm{Y}$ molar deposits had the maximum value. A different representation of the data elucidates this more clearly [Fig. 2(b)]. The Cu/Ba ratio was close to 1.5 at its minimum as in the $\mathrm{YBCO}$ target, and increased at both ends, especially at low laser fluence [Fig. 2(a)]. The $\mathrm{Y} / \mathrm{Ba}$ molar ratio was also found to peak near $0^{\circ}$. Although the number of the data points in Figs. 2(a) and 2(b) was small, similar results were observed in several different runs. More-

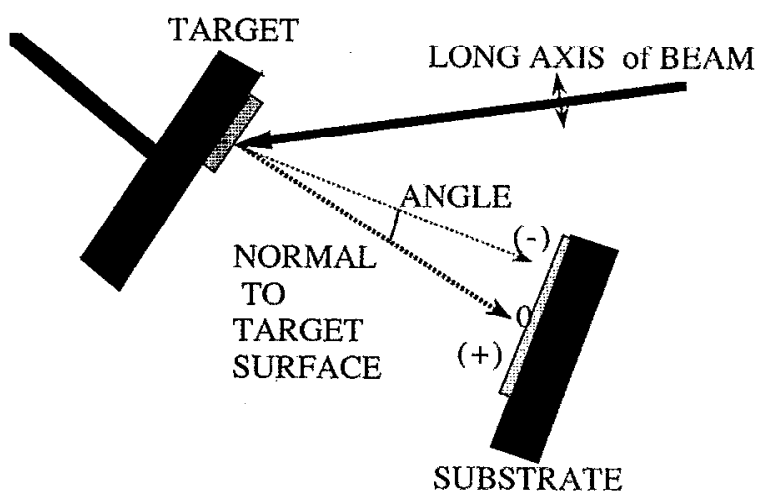

FIG. 3. Definition of the coordinates used in Fig. 2(a). The angle was defined in the plane where the incident laser beam and the normal to the target surface lay. The angle $0^{\circ}$ is on the normal to the target at its center. 


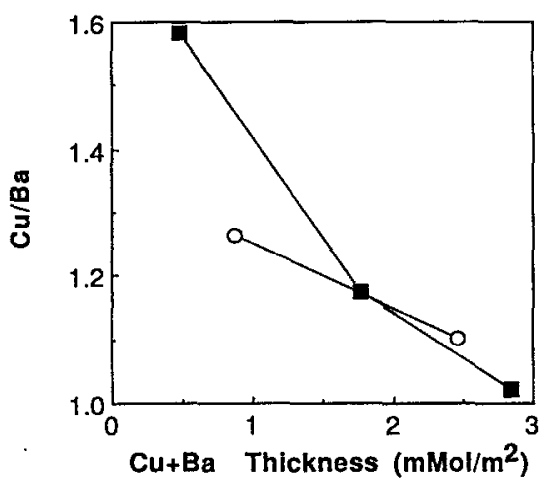

FIG. 4. Distribution of $\mathrm{Ba} / \mathrm{Cu}$ molar ratio of the films deposited at 0.85 $\mathrm{J} / \mathrm{cm}^{2}$ at R.T. using $\mathrm{BaCuO}_{2}$ target plotted in the same manner as in Fig. 2(b). The symbols correspond to data of different runs.

over, the $\mathrm{Cu} / \mathrm{Ba}$ ratios in the films deposited with $\mathrm{BaCuO}_{2}$ had also the minimum at the position where the total deposit had the maximum (Fig. 4).

The above results show that the compositional distributions in the absence of an ambient gas at a low laser fluence were partly different from the theory predictions and from the previous experimental results. Contrarily to the present observations the $\mathrm{Cu} / \mathrm{Ba}$ ratio ${ }^{15}$ and the $\mathrm{Y} / \mathrm{Ba}$ ratio ${ }^{15,16}$ in the films deposited with YBCO targets were reported to have the maximum where the molar deposit peaked.

\section{Possible explanation of the angular distribution of deposited elements}

The theories of pulsed laser evaporation process, ${ }^{17-19}$ which were based on a thermal process, assumed a uniform heating of stoichiometric materials such as YBCO, neglecting collision of evaporated materials with an ambient gas.

In the theory by Singh and Narayan, ${ }^{18}$ composition and thickness distributions result from the velocity differences of different elements. Namely, the velocity component normal to target surface is roughly proportional to $\sqrt{\left(T_{p} / M\right)}$, where $T_{p}$ and $M$ are plasma temperature of the evaporated element and atomic weight of the element, respectively. Since the velocity component parallel to the target surface depends less on $T_{p}$ than its perpendicular component, the velocity vector increasingly aligns to the normal to the target surface as $T_{p}$ increases [Figs. 10(a) and 13 and Tables I and III of Ref. 18]. Distribution of the velocity vector can be projected into that of the thickness variation of the deposited film (Fig. 5), which successfully explained the previous experimental observations. ${ }^{18}$ When evaporation from a uniform stoichiometric surface is assumed, $T_{p}$ is the same for different kinds of elements. Therefore, the velocity component normal to the target surface is larger for lighter elements. This means that lighter elements have narrower thickness distribution on a film surface. Accordingly, $\mathrm{Cu}$ should have the narrowest thickness distribution, and $\mathrm{Ba}$ should have the widest among $\mathrm{Cu}, \mathrm{Ba}$, and $\mathrm{Y}$ when they are evaporated from a YBCO target.

Contrarily to the assumption in these theories, several studies $^{20,21}$ experimentally showed a change of target surface composition by laser irradiation. Additionally, we have observed a change in the surface metal composition as well as
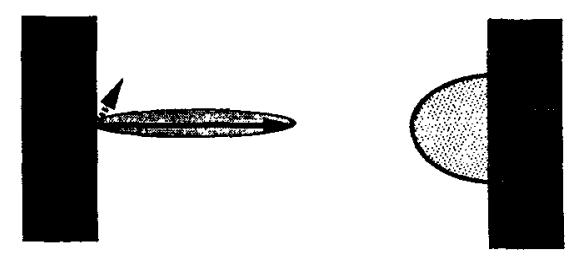

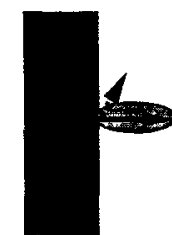

target

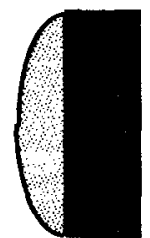

substrate
FIG. 5. Illustration of relation of the velocity component normal to target with the thickness distribution.

the oxidation state by laser irradiation, using $x$-ray photoelectron spectroscopy. ${ }^{22}$ Therefore, we consider the effect of a compositional nonuniformity in these theories. It is worth noting that $\mathrm{YBCO}$ is only stable below $1000^{\circ} \mathrm{C}$ even in the air, ${ }^{23}$ while the target surface should be heated above a few thousand degrees at low oxygen pressure in a usual deposition condition. Therefore, we assume that the surface of a stoichiometric YBCO target is decomposed into simpler materials which are stable at a high temperature such as $\mathrm{CuO}_{x}$, $\mathrm{BaCuO}_{x}, \mathrm{BaO}_{x}$, and $\mathrm{YO}_{x}$.

To elucidate the effect of target surface decomposition on the thickness distribution, we have considered the simplest case where a YBCO target surface was decomposed into $\mathrm{Cu}, \mathrm{Ba}$, and $\mathrm{Y}$. They were chosen since their material parameters necessary for calculation of the laser heating process were all known. The result should be sufficient to illustrate the decomposition effect. Three-dimensional temperature profiles of the target surface irradiated by an $\mathrm{ArF}$ laser were estimated using a finitc clement method. In these calculations, a target surface area of $3 \times 6 \mathrm{~mm}^{2}$ was assumed to he irradiated by an ArF laser at a power density of $1 \mathrm{~J} / \mathrm{cm}^{2}$ for 10 ns. Figure 6 shows an example of the two-dimensional temperature profile of the $\mathrm{Y}$ surface $10 \mathrm{~ns}$ after starting of

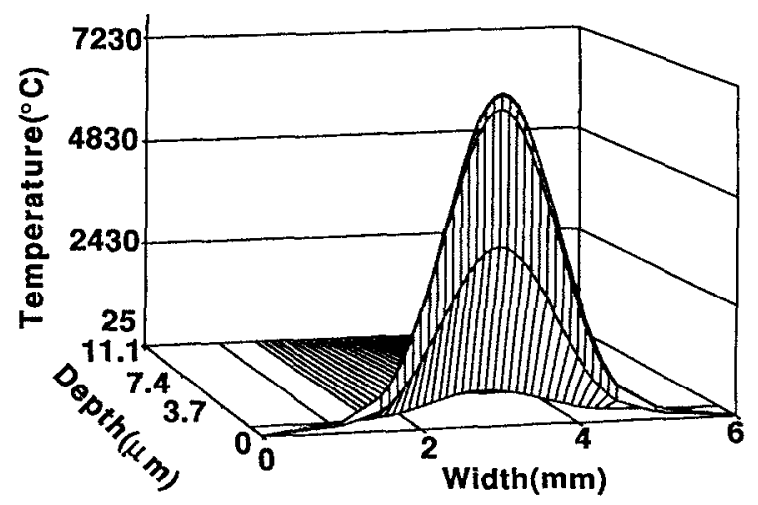

FIG. 6. Two-dimensional temperature profile of $Y$ surface $10 \mathrm{~ns}$ after starting of laser irradiation. The surface is irradiated by a beam of $6 \mathrm{~mm}$ wide and $3 \mathrm{~mm}$ long. 


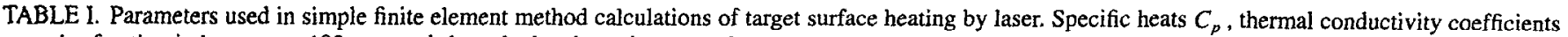
$\kappa$, and refractive indexes near $193 \mathrm{~nm}$, and the calculated maximum surface temperature $T_{\max }$ and the calculated most probable velocities $v$ are listed.

\begin{tabular}{|c|c|c|c|c|c|}
\hline Material & $C_{p}(\mathrm{~J} / \mathrm{mol} / \mathrm{deg})$ & $\kappa(\mathrm{W} / \mathrm{mK})$ & $(n, k)$ & $T_{\max }\left({ }^{\circ} \mathrm{C}\right)$ & $v\left(\mathrm{a} . \mathrm{u}_{\mathrm{.}}\right)$ \\
\hline $\mathrm{YBCO}$ & -50 & $5-10$ & $(1.74,0.62)$ & 3200 & \\
\hline $\mathrm{Ba}$ & 26 & -20 & $(0.69,0.87)$ & 6000 & 1.07 \\
\hline$Y$ & $25-30$ & 20 & $(1.04,0.6)$ & 6300 & 1.38 \\
\hline $\mathrm{Cu}$ & $25-30$ & 370 & $(1.036,1.59)$ & 1000 & 0.65 \\
\hline
\end{tabular}

laser irradiation, and that the heating was confined within $1000 \AA$ from the surface. Table I summarizes the parameters used and the calculated maximum temperature of $\mathrm{YBCO}, \mathrm{Y}$, $\mathrm{Ba}$, and $\mathrm{Cu}$ surfaces. The plasma temperature $T_{p}$ is roughly given by $k_{B} T_{\max }-\mathrm{Ev}$, where $T_{\max }, k_{B}$, and $\mathrm{Ev}$ are the maximum temperature, the Boltzmann constant, and the evaporation heat, respectively. If $k_{B} T_{\max } \gg \mathrm{Ev}$, then $T_{p} \sim T_{\max }$, and the velocity component normal to the target is approximately $\sqrt{\left(T_{\max } / M\right)}$. Therefore, Ba gains the highest normal velocity component among $\mathrm{Y}, \mathrm{Ba}$, and $\mathrm{Cu}$, and $\mathrm{Cu}$ gains the lowest. In these calculations we have assumed no melling, no evaporation of the target, and no radiation heating loss from the target during laser heating.

The experimentally obtained most-probable velocities for $\mathrm{Cu} \mathrm{I}, \mathrm{YI}, \mathrm{Ba} \mathrm{I}$, and $\mathrm{Ba}$ II were $1.12,0.97,0.82$, and 1.12 $\left(\times 10^{4} \mathrm{~m} / \mathrm{s}\right),{ }^{24}$ when an YBCO target was irradiated by an ArF laser at $5.3 \mathrm{~J} / \mathrm{cm}^{2}$ at the ambient pressure of $\sim 10^{-5}$ Torr. Here the Roman numbers $l$ and II indicate a neutral and a singly ionized atom, respectively. The kinetic energy of the neutral elements estimated from these velocities was larger for heavier element, while the kinetic energy of Ba II was more than twice of that of $\mathrm{Cu}$. Furthermore, identification of excited atoms critically depends on the spectrometer range. According to a more precise measurement, the major components in the plume near the target were found to be $\mathrm{Cu} \mathrm{I}$, $Y \mathrm{I}, \mathrm{Y}$ II, and $\mathrm{Ba} I \mathrm{I}$, when they were generated from an YBCO target by a $\mathrm{KrF}$ laser at $3 \mathrm{~J} / \mathrm{cm}^{2} .{ }^{25}$ Combining these two observations we can deduce that $\mathrm{Ba}$ had a kinetic energy much larger than $\mathrm{Cu}$. Moreover, the velocities of $\mathrm{Sr}, \mathrm{Ca}$, and $\mathrm{Cu}$ evaporated from $\mathrm{BiSrCaCuO}$ target a $\mathrm{KrF}$ laser at 1-2 $\mathrm{J} / \mathrm{cm}^{2}$ were $1.6-2.0,1.3-1.5$, and 1.2 at an oxygen pressure of $10^{-3} \mathrm{mbar}^{26}$ These experimental results are consistent with the present results and not with the previous theories predicting the highest normal velocity for the light element (Cu). ${ }^{17,18}$

Following the arguments of the previous theories, the magnitude of the normal velocity corresponds to the thickness distribution narrowness (Fig. 5). Therefore, Ba is estimated to have the narrowest thickness distribution, and $\mathrm{Cu}$ is estimated to have the widest. The results agree with the experimental results in Sec. II A 2. Here we did not consider the resputtering effect in PLD as suggested for $\mathrm{Pb}(\mathrm{Ti}, \mathrm{Zr}) \mathrm{O}_{3}$ films. ${ }^{27}$ Although backscattering of $\mathrm{Ba}$ was also suggested, ${ }^{28}$ the resputtering effect on the thickness distribution was limited even in the case of $\mathrm{Pb}(\mathrm{Ti}, \mathrm{Zr}) \mathrm{O}_{3}$ despite a high laser power density of $4 \mathrm{~J} / \mathrm{cm}^{2}$ and despite the volatile nature of $\mathrm{Pb}^{27}$ Therefore, the above arguments would be essentially unaltered, even if we consider the resputtering effect at a relatively low laser power density $<1 \mathrm{~J} / \mathrm{cm}^{2}$. It would be worth noticing that particulates on the YBCO films having a different composition from YBCO such as $\mathrm{CuO}_{x}$ can be understood in our model.

\section{Summary of low-power PLD and discussion}

It is generally accepted that there is a tradeoff among particulate density, precipitate density, and electrical and crystallographic properties, when a given kind of target material is used as a target in a PLD. Namely, particulates were observed to reduce at a low laser power density, e.g., $\sim 1$ $\mathrm{J} / \mathrm{cm}^{2}$ for YBCO. However, use of such a low laser power density degraded the film stoichiometry, resulting in growth of precipitates or surface roughing at the substrate temperature $T_{s}$ suitable to obtain good crystallographic and electrical properties, and precipitates were observed to reduce by lowering $T_{s}$ and by slightly degrading electrical and crystallographic properties. We show this relation schematically in Fig. 7. The results in Secs. II A 2 and II A 3 suggest that, in general, this tradeoff is difficult to overcome as long as a single target having complex composition is used. Furthermore, the above results indicated that a target surface of a multicompositional material irradiated over time can be regarded as an assembly of many small targets consisting of materials of a simpler composition (Fig. 8). Therefore, there seems to be no very good advantage of using a single target in PLD, when exact control of the film composition is required.

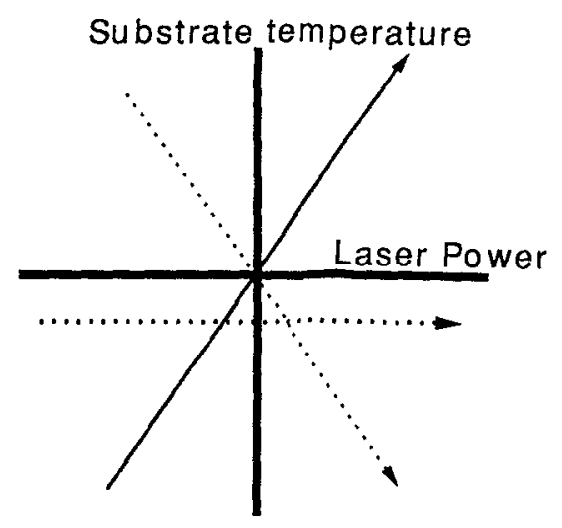

FIG. 7. Empirical relation of electrical and crystallographic properties, surface morphology with laser power density, and $T_{s}$ for PLD of a given multicompositional film. Solid lines show inprovements of electrical and crystallographic properties, the horizontal dashed line shows the improvement of stoichiometry and the increase of particulate, and the oblique dotted line shows decrease of precipitates. 

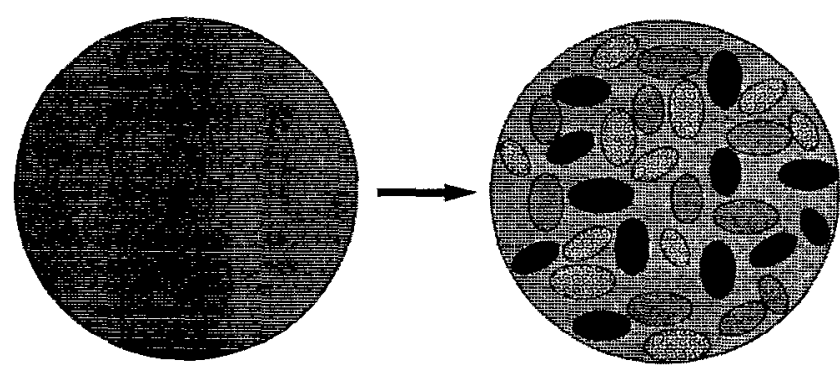

FIG. 8. Schematic illustration of target surface composition before and after a low-fluene latse uradiation. The surface of the latter contains small domains of different compositions more stable at a high temperature than the original surfice. The turget can be effectively regarded as a microscopic mosaic target.

\section{B. $\mathrm{YBa}_{2} \mathrm{Cu}_{3} \mathrm{O}_{7}$ films by RSPLD}

\section{Basic concepts of RSPLD}

The above arguments illustrated problems in conventional PLD. Additionally, we have reported a marked reduction of particulate density and particulate size by reducing laser power density and by using an alloy or metal targets. ${ }^{14}$ However, an alloy having the desired composition such as $\mathrm{YBa}_{2} \mathrm{Cu}_{3}$ for $\mathrm{YBCO}$ could not often be formed in a thermodynamic equilibrium, and some alloys may not be suitable to reduce particulates.

To solve these problems, we have examined a possibility of pulsed laser codeposition, since it allowed free choices of target materials and laser power density as well as a good control of the film composition. There should be several ways to realize or simulate a pulsed laser codeposition such as use of multiple pulse lasers and use of a multibeam path by using beam splitters in a single pulse laser system. Unfortunately, the laser power density in the latter is reduced and is sometimes insufficient. Instead of these real codepositions, a sequential deposition can be employed.

In a conventional sequential deposition technique such as layer-by-layer sequential deposition, a few disadvantages have existed in electrical and crystallographic properties and surface morphology. In sequentially deposited cuprate films, reduced eleetrical and crystallographic properties have been reported as well as growth of secondary phases on the tilms. ${ }^{29-33}$ The formation of secondary phases in layer-bylayer sequential depositions of $(\mathrm{Sr}, \mathrm{Ca}) \mathrm{CuO}_{2}$ films was attributed to a local nonstoichiometric composition by Kanai and co-workers. ${ }^{29}$ To avoid this problem, an average composition deviation from the stoichiometry at the film surface should be small, and duration of the deviation period should also be as short as possible (Fig. 9). To accomplish this, the time interval between the irradiations of different kind of targets was chosen to be short, typically, $0.01 \mathrm{~s}$, and the deposit by each laser shot was adjusted to be small, typically, 0.001 $A /$ shot. For this reason, we call this version of PLD RSPLD.

To fulfill these requirements, the laser power density needs to be adjusted suitably for each target, because of a critical dependence of evatporation rate on a target material, and this adjustment should be responsive. A RSPLD system was assembled to meet these requirements (Fig. 10). The

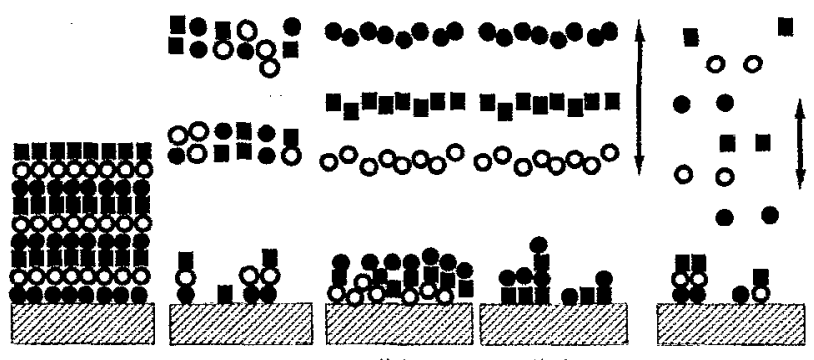

(a)

(b)

(b')

(c)

FIG. 9. Schematic diagram showing deposition process of an oxide $\mathrm{ABCO}_{x}$ film (shown in the left-hand-side most figure) by three methods partly adopted from Ref. 12: (a) conventional PI D; (b) layer-by-layer deposition at a low $T_{s}$; (b') layer-by-layer deposition at a high $T_{y}$; (c) RSPI.D. Metal elements $A, B$, and $C$ are denoted by a solid circle, open circle, and square, respectively. The arrows show time scales of one cycle which are typically $1 \mathrm{~min}$ in $(\mathrm{b})$ and $\left(\mathrm{b}^{\prime}\right)$ and $0.1 \mathrm{~s}$ in $(\mathrm{c})$. The $\mathrm{ABCO}_{x}$ film has a crystal structure of $A B C A B C A B C$ as shown in the left-hand-side most figure. This can grow at given temperature and pressure if a correct stoichiometric amount of adatoms is supplied. If a certain element, e.g., B, is absent for a while at an elevated $T_{s}$, a secondary phase $\mathrm{AC}$ grows as shown in $\left(\mathrm{b}^{\prime}\right)$ due to migration of adatoms. This can be sufficiently suppressed at a low $T_{s}$ at the expense of cystallinity.

stoichiometry of a film is controlled by the power density and the number of laser shots on each target per cycle, i.e., per rotation of the target holding carousel.

YBCO films grown by PLD exhibit a higher than average number of particulates compared to films of other oxide materials. Therefore, we demonstrate the results of YBCO film deposition by RSPLD in the subsequent two subsections. The use of $\mathrm{Cu}, \mathrm{Ba}$, and $\mathrm{Y}$ metals as target is ideal for deposition of YBCO, if possible. However, the evaporation rate of $\mathrm{Cu}$ at a power density of a few $\mathrm{J} \mathrm{cm}^{-2}$ was extremely low. Therefore, $\mathrm{Ba}$ and $\mathrm{YCu}_{3}$, or $\mathrm{BaCu}$ and $\mathrm{YCu}$, were used after having examined the deposition rate and morphology of films deposited at room temperature. ${ }^{14} \mathrm{Y}, \mathrm{Ba}$, and $\mathrm{Cu}$ atoms

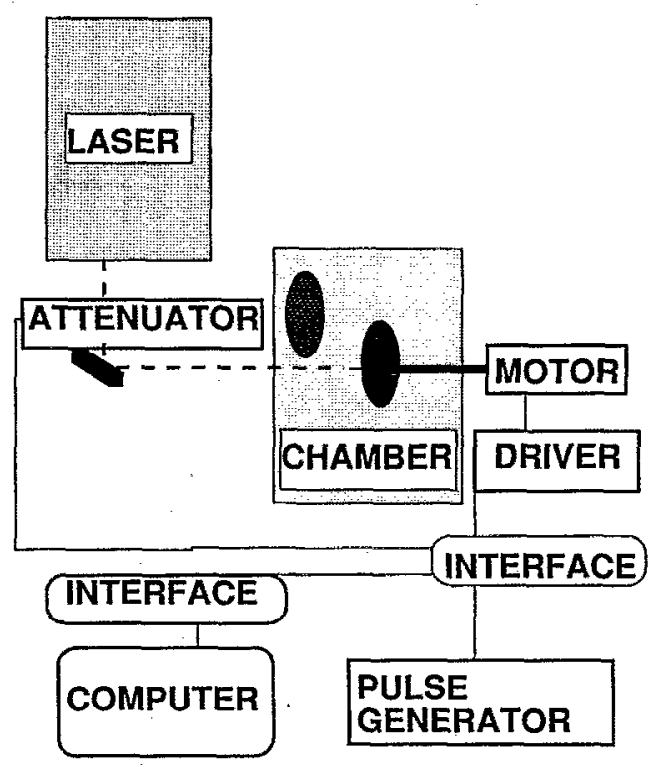

FIG. 10. Deposition system diagram. The attenuator and the laser are synchronized with rotation of the target holder carousel. 


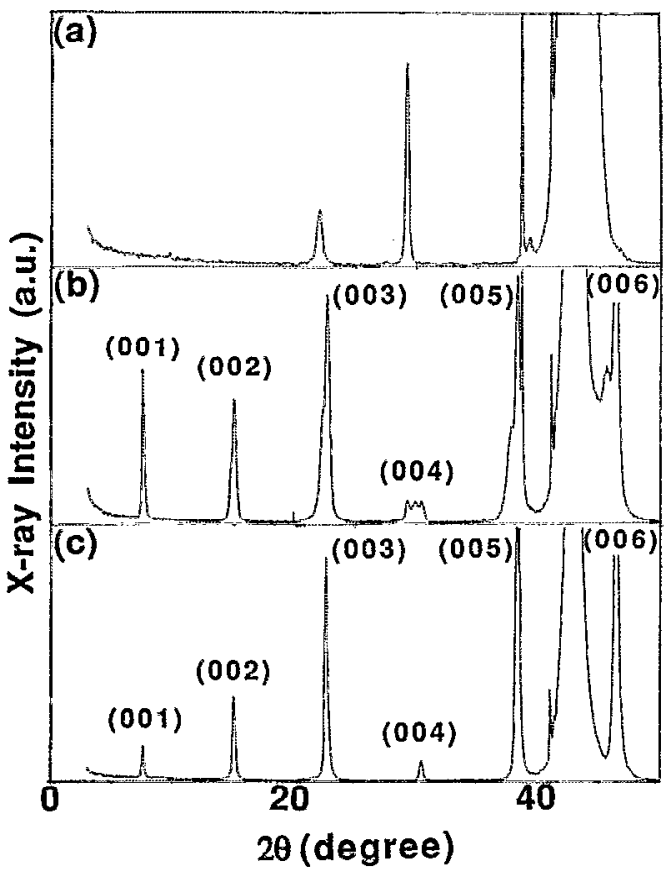

FIG. 11. $9 / 2 \Theta x$-ray-diffractometer patterns YBCO films on $\mathrm{MgO}(100)$ substrates having different composition (a) $\mathrm{Y}: \mathrm{Ba}: \mathrm{Cu}=1: 3.58: 3.58$, (b) $\mathrm{Y}: \mathrm{Ba}: \mathrm{Cu}=1: 2.69: 10.3$, (c) $\mathrm{Y}: \mathrm{Ba}: \mathrm{Cu}=1: 1,67: 2.99$. Film (a) was deposited at $T_{s}=600^{\circ} \mathrm{C}$, and films (b) and (c) were deposited at $T_{s}=650^{\circ} \mathrm{C}$.

with molar ratio of 1:2:3 are deposited onto the substrate in one cycle of $100-200 \mathrm{~ms}$.

\section{YBCO deposition using $\mathrm{BaCu}$ and YCu targets}

It should be noted that $\mathrm{BaCu}$ and $\mathrm{YCu}$ correspond to metal compositions of the block layers of YBCO, e.g., $\mathrm{BaCuO}_{\mathrm{r}} / \mathrm{YCuO}_{\mathrm{r}} / \mathrm{BaCuO}_{\mathrm{r}}$. Figures 11 and 12 show the $\Theta / 2 \Theta$ $x$-ray-diffractometer patterns of YBCO films and their SEM pictures, respectively. Figures 12(a)-12(c) correspond to Figs. 11(a)-12(c), respectively, and Figs. 12(d)-12(f) are their higher magnifications. YBCO was deposited onto $1 \mathrm{~cm}^{2}$ MgO (100) substrates. The ambient molecular oxygen pressure and $T_{s}$ were $100 \mathrm{mTorr}$ and $650^{\circ} \mathrm{C}$ for the films in Figs. $11(\mathrm{~b})$ and $11(\mathrm{c})$, and $70 \mathrm{mTorr}$ and $600^{\circ} \mathrm{C}$ for the film in Fig. 11 (a), respectively. The energy density was $1.2 \mathrm{~J} / \mathrm{cm}^{2}$ [Figs. 11(b) and 11(c)] or $0.8 \mathrm{~J} / \mathrm{cm}^{2}$ [Fig. 11(a)] for both $\mathrm{BaCu}$ and $\mathrm{YCu}$ targets, and the laser shot number on each target was adjusted to one per cycle for $\mathrm{BaCu}$ and to 1-3 per cycle for $\mathrm{YCu}$. The deposition rate ratio of $\mathrm{BaCu}$ target to that of $\mathrm{YCu}$ target increased as the energy density decreased. The indexed peaks correspond to $(00 l)$ peaks from c-axis-oriented $\mathrm{YBCO}$, and the others were assigned to secondary phases such as $\mathrm{BaCuO}_{z}$. The composition of the large dark spots observed on Fig. 12(c) as analyzed by EDX was the same as the other part of the film. The stripes in Fig. 12(f) may correspond to the $a$ - or $b$-axis domains. Differently from particulates, the particles in Figs. 12(d) and $12(\mathrm{e})$ had irregular shapes and composition of $\mathrm{BaCuOx}$ as analyzed by EDX. These particles and the $x$-ray-diffraction peaks from secondary phases diminished as the average film composition approached the stoichiometric value. Therefore, it can be concluded that particulates were substantially reduced with the (a)

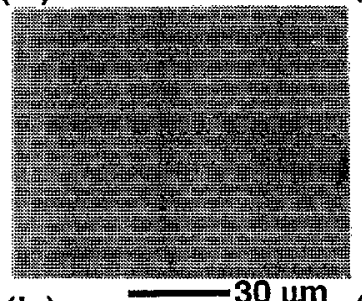

(b)

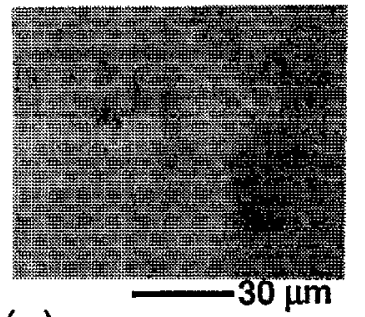

(c)

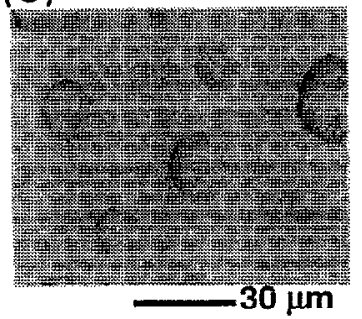

(d)

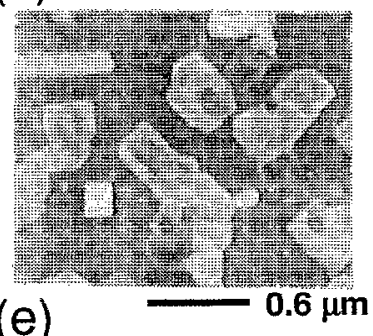

(e)

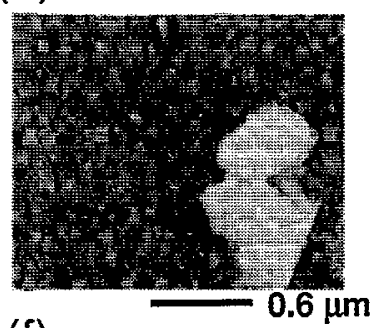

(f)

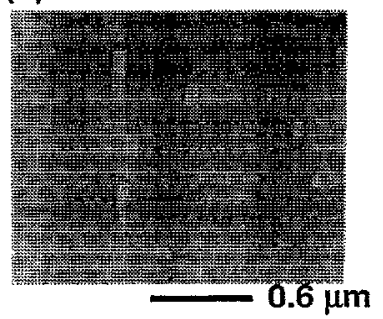

FIG. 12. SEM pictures of YBCO films of which $\theta / 2 \theta x$-ray-diffractometer patterns are shown in Fig. 11. (a)-(c) correspond to Figs. 11(a)-11(c), and (d)-(f) show higher magnifications of (a)-(c).

RSPLD method. The films of Figs. 12(b) and 12(c) showed zero resistance at 80 and $87 \mathrm{~K}$, respectively, while their thicknesses were 500 and $350 \AA$.

\section{3. $\mathrm{YBCO}$ deposition using $\mathrm{Ba}$ and $\mathrm{YCu}_{3}$ targets}

Homogeneous YBCO was deposited onto $1 \mathrm{~cm}^{2} \mathrm{SrTiO}_{3}$ (100) and $\mathrm{MgO}$ (100) substrates. Typical energy densities were about $0.2 \mathrm{~J} / \mathrm{cm}^{2}$ for Ba target and about $1.5 \mathrm{~J} / \mathrm{cm}^{2}$ for $\mathrm{YCu}_{3}$ targets, and the average deposition rate was $10-20$ $\AA / m i n$. Figures $13(\mathrm{a})$ and $13(\mathrm{c})$ show the $\Theta / 2 \Theta x$-raydiffractometer patterns of films on MgO, while Figs. 13(b) and 13(d) show those of films on $\mathrm{SrTiO}_{3}$. The films in Figs. 13 (c) and 13(d) had stoichiometric average compositions, and films in Figs. 13(a) and 13(b) had off-stoichiometric average compositions. The number of laser shots was one per cycle for Ba and two per cycle for YCu for the film in Figs. $13(\mathrm{c})$ and 13(d), and was one per cycle for Ba and three per cycle for $\mathrm{YCu}$ for the film in Figs. 13(a) and 13(b). Both films were deposited at $T_{s}=650^{\circ} \mathrm{C}$ and at a molecular oxygen pressure of $100 \mathrm{~m}$ Torr, and their thicknesses were about $500 \AA$. The dominant $(00 l)$ peaks indicate that the samples were $c$-axis oriented with the [001] direction perpendicular to the film surface. The $c$-axis lattice constants calculated from the $(00 l)$ peaks of these samples agreed with the bulk value within $0.3 \%$. This suggests that the films were well oxidized despite the use of metal targets.

The SEM pictures shown in Figs. 14(a) and 14(b) and Figs. 15(a) and 15(b) correspond to Figs. 13(a)-13(d), re- 


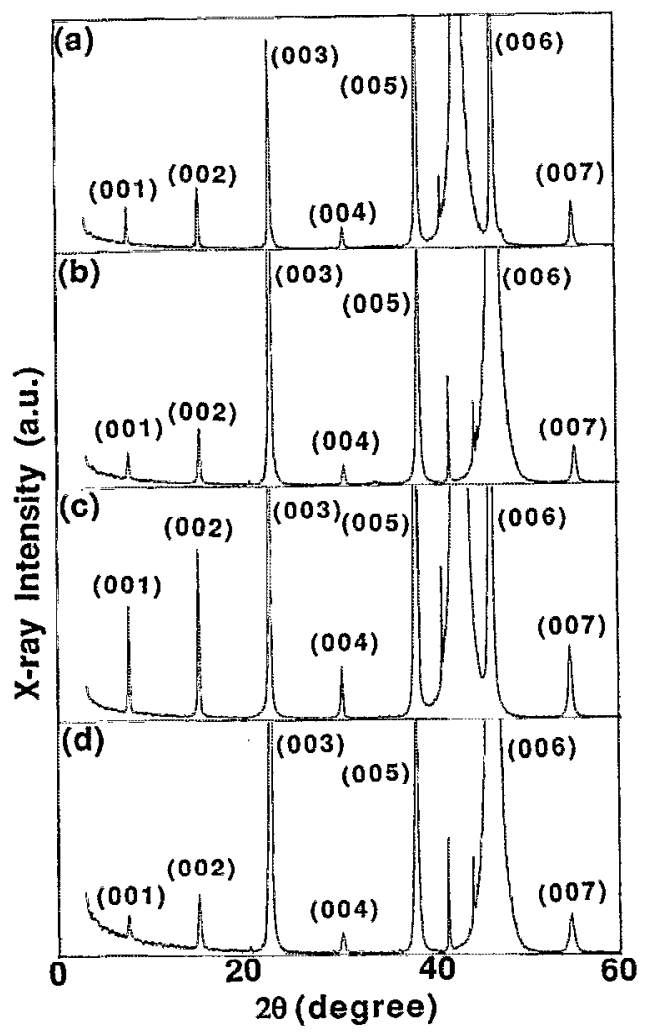

FIG. 13. $\Theta / 2 \Theta x$-ray-diffractometer patterns of YBCO films on MgO(100) $[(a),(c)]$ and $\mathrm{SrTiO}_{3}[$ (b), (d)] substrates having different composition: (a),(b) $Y: B a: C, u=1: 1,4: 2.9$ and $(\mathrm{c}),(\mathrm{d}) \mathrm{Y}: \mathrm{Ba}: \mathrm{Cu}=1: 2,1 ; 3,1$. The films were deposited at $T_{s}=6500^{\circ} \mathrm{C}$

spectively, and Figs. 14(c) and 14(d) and Figs. 15(c) and 15 (d) are their higher magnifications. Particles were found in Figs. 14(a)-14(d), and $x$-ray diffraction showed the presence of impurity phases in these films. These particles had compositions different from the matrix, e.g., $\mathrm{CuO}_{x}$ as analyzed by EDX. In Figs. 15(a)-15(d) particles were drastically reduced in number and size. The dark lines and dark dots in

(a)

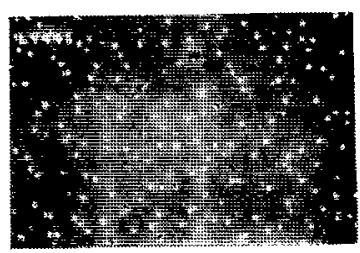

(b)

(c)

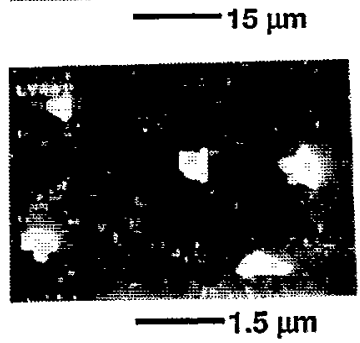

(d)
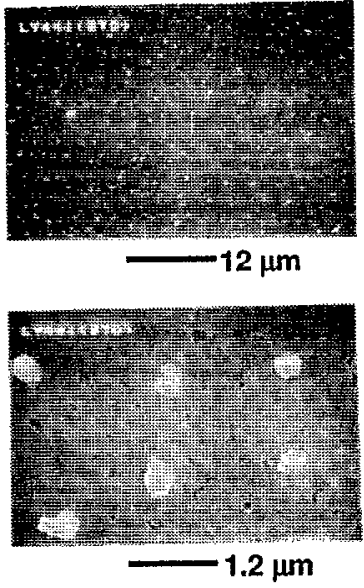

(a)

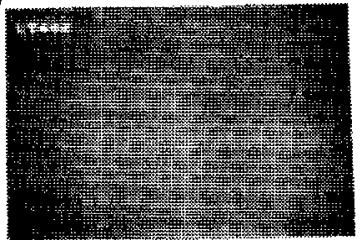

$-30 \mu \mathrm{m}$

(c)

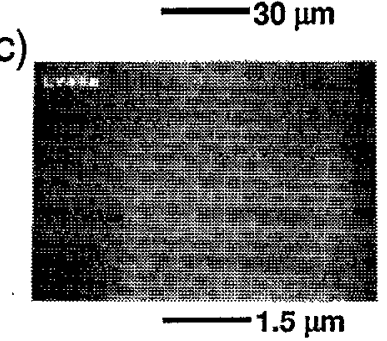

(b)

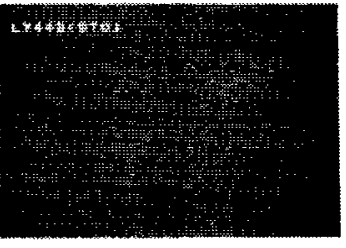

(d)
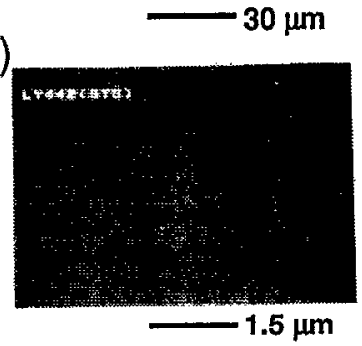

FIG. 15. (a),(h) SEM pictures of XBCO films and (c), (d) their higher magnifications of which $x$-ray-diftractometer patterns are shown in Figs. 13(c) and 13(d). (a),(c) and (b).(d) correspond to (c) $\mathrm{MgO}$ substrate and (d) $\mathrm{SrTiO}_{3}$ substrate in Fig. 13, respectively.

Fig. 15(c) are the surface damages of the substrate which were also observed on as-received substrates. Figures $15(\mathrm{a})-$ 15(d) demonstrate that no particulates were observed, and that only a few precipitates smaller than $0.1 \mu \mathrm{m}$ were observed in an area of $100 \times 100 \mu \mathrm{m}^{2}$. Particles were reduced not only by adjusting the average composition but also by reducing $T_{s}$ as shown in Figs. 16(a) and 16(b). This film was deposited at $T_{s}=600^{\circ} \mathrm{C}$ at and oxygen pressure of $60 \mathrm{mTorr}$. Therefore, we concluded that these particles were precipitates formed on the films as previously discussed..$^{10,11}$ No particles larger than a $0.5 \mu \mathrm{m}$ were observed on the entire surface of the films as long as the film had an exact stoichiometry. No particulates were identified by shape and size $\left(>0.5 \mu \mathrm{m}\right.$ diameter) in a $1 \times 1 \mathrm{~mm}^{2}$ area of the film surface

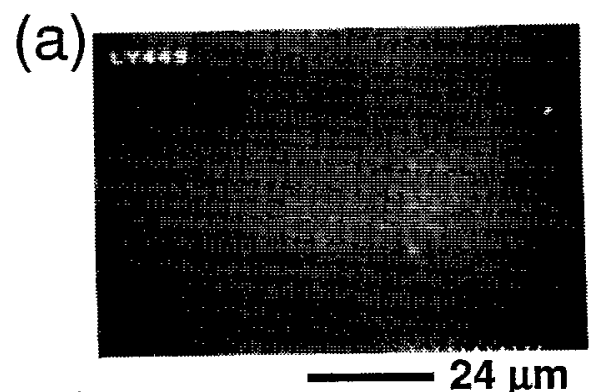

FIG. 14. (a),(b) SEM pictures of YBCO films and (c),(d) their higher magnifications of which $x$-ray diffractometer patterns are shown in Figs. 13(a) and 13(b). (a),(c) and (b), (d) correspond to (a) $\mathrm{MgO}$ substrate and (b) $\mathrm{SrTiO}_{3}$ substrate in Fig. 13, respectively.

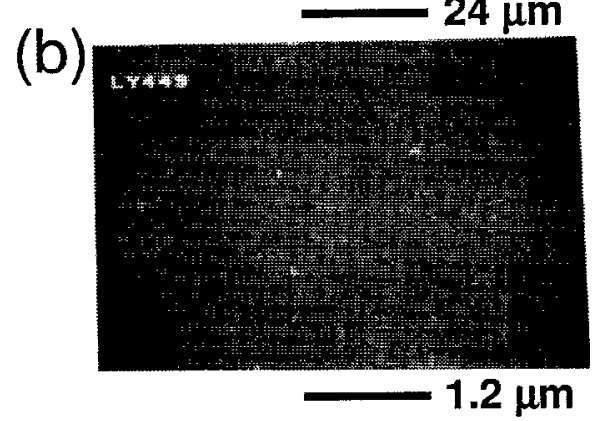

FIG. 16. SEM picture of (a) an YBCO film on a MgO (100) substrate and (b) its higher magnification which was deposited at $T_{s}=600^{\circ} \mathrm{C}$. The white spot at the upper right-hand-side comer is dust used for focusing. 


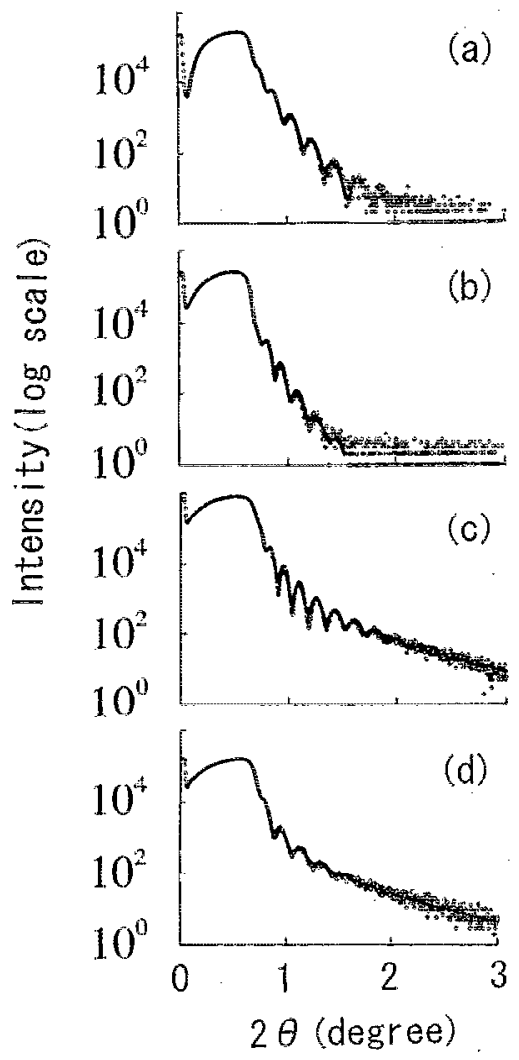

FIG. 17. Grazing-incidence $x$ ray reflectivity patterns of YBCO films. (a)(d) correspond to the films in Figs. 14(d), 15(d), 15(c), and 16(b).

even after the targets were used for more than ten runs. The films on $\mathrm{SrTiO}_{3}$ of Figs. 14(b) and 15(b) showed zero resistance at 90 and $80 \mathrm{~K}$, respectively, while those on $\mathrm{MgO}$ of Figs. 14(a), 15(a), and 16 did at 88,72 , and $77 \mathrm{~K}$, respectively.

The roughness of the surface and the film/substrate interface was evaluated by the grazing incidence $x$-ray reflectivity (GIXR) method. ${ }^{13}$ The $x$-ray intensity oscillations of the films on $\mathrm{SrTiO}_{3}$ decay faster than those of the films on $\mathrm{MgO}$. The average peak-to-valley values of the roughness were $35 \AA$ ( $26 \AA$ ) for Fig. 17(a), $37 \AA$ (44 $\AA$ ) for Fig. 17(b), $6 \AA(26 \AA)$ for Fig. 17(c), and $3 \AA(37 \AA)$ for Fig. 17(d) at the film surface, where the values in parentheses indicate the roughness at the film/substrate interface. As is evident from comparison of these roughness estimations with SEM pictures in Fig. 14-16, the precipitates did not affect the surface roughness estimation by GIXR.

\section{DISCUSSION}

\section{A. Surface morphology of YBCO and its substrate dependence}

Two kinds of precipitates were found on the films on MgO as shown in Figs. 14-16. One had an irregular shape, a typical size of $0.5-1 \mu \mathrm{m}$, and composition of $\mathrm{CuO}_{x}$, and the other had a rectangular shape and length of $0.1-0.2 \mu \mathrm{m}$. The long axes of the latter precipitates were aligned to one of the two directions which were mutually perpendicular. This suggested the effect of the substrate $a$ axis on the orientation of

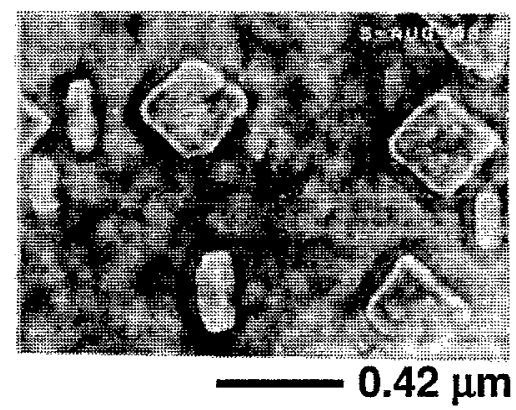

FIG. 18. SEM picture of an YBCO film on a $\mathrm{MgO}(100)$ substrate of which the composition was close to that of $\mathrm{BaCuO}_{2}$.

this type of precipitate. Only the former type of precipitate was found on the films on $\mathrm{SrTiO}_{3}$. Moreover, the grain boundaries easily identified on the films on $\mathrm{MgO}$ were not observed on those on $\mathrm{SrTiO}_{3}$. However, it seems that the surface roughness detected by GIXR was not affected by presence of the grain boundaries. These results suggest a different growth mechanism of $\mathrm{YBCO}$ films on $\mathrm{MgO}$ and $\mathrm{SrTiO}_{3}$ substrates.

Particles which were probably particulates coming from targets were occasionally observed on the films deposited with $\mathrm{YCu}$ and $\mathrm{BaCu}$ targets (Fig. 12). By studying surface morphology of the films deposited at room temperature using $\mathrm{BaCu}$ and $\mathrm{YCu}$ targets, it was found that the $\mathrm{BaCu}$ target tended to yield $\mathrm{Cu}$ particulates. ${ }^{14}$ This was the probably the reason that more particulates were observed in Fig. 12 than in Figs. 14-17. However, the particulates were much more reduced than expected from surface morphology of the films deposited at room temperature using these targets. This may be due to the radiative heating of the target by the substrate heater or to a possible melting of metal/alloy particulate on the film as discussed in Ref. 14. Accordingly, the dark spots in Fig. 12(c) may have been formed by change of local composition by melting of particulates.

- The deposition cycle in RSPLD employed here was only a few orders of magnitude shorter than those in conventional layer-by-layer sequential depositions. We thought that this might not be sufficient to suppress the secondary phase growth. Nevertheless, the experimental results demonstrated the simultaneous suppression of secondary phases growth and achievement of the high electrical properties in films having stoichiometric composition.

\section{B. Films having composition close to $\mathrm{BaCuO}_{2}$ : Formation of unstable phase}

Films having composition close to $\mathrm{BaCuO}_{2}$ were obtained using $\mathrm{BaCu}$ and $\mathrm{YCu}$ targets. Well-developed secondary phases are visible in Fig. 12(d). The films having a similar morphology was also deposited using $\mathrm{Ba}$ and $\mathrm{YCu}_{3}$ targets as shown in Fig. 18, which exhibited well-defined squares. Only small peaks of $\mathrm{BaCuO}_{2}$ were identified in the $x$-ray diffractometer patterns of these films. The films were semi-insulating; however, the films, especially the one shown in Fig. 18, were unstable. Namely, within a few minutes after takeout from the growth chamber its color changed from brownish black to brown, its surface roughness as observed 


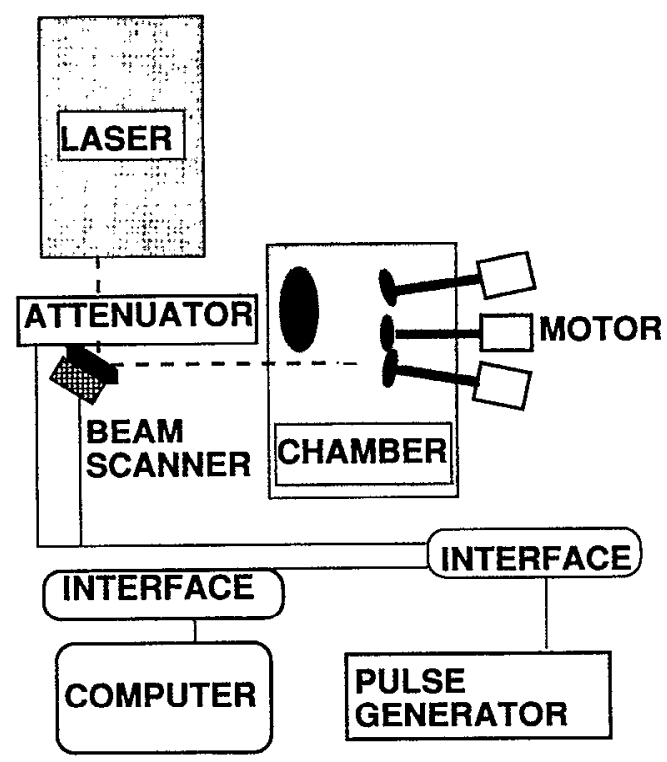

FIG. 19. Schematic diagram of another KSPLD setup which enables fast deposition by using a scanning laser beam instead of a target holder carousel.

by optical microscope degraded rapidly, and its resistance increased until it became semi-insulating. These properties and the square shape in Fig. 18(b) suggest a possibility that the compound formed before exposure to the air might be $\mathrm{BaCuO}_{2}$ having an infinite layer structure as $\mathrm{SrCuO}_{2} \cdot{ }^{34}$

\section{Demerits of RSPLD and their improvements}

The first demerit of RSPLD or pulsed laser quasicodeposition is the complexity inherent in the use of multitargets and free choice of target material itself. There are many different combinations of targets which allow deposition of a desired film; therefore, it is necessary to determine which combination is the best before optimizing deposition condition. The use of metal targets and targets having simple compositions has been effective to eliminate and particulate.

Another demerit is a low deposition rate of which the maximum value was $500 \AA / 20 \mathrm{~min}$ at $\mathrm{T} / \mathrm{S}=8 \mathrm{~cm}$. We cannot increase the laser power density much, because it causes particulate formation, but we can shorten the deposition cycle period. Here, the deposition cycle period in our system is limited by the rotation speed of the target holder carousel. To overcome this problem, we propose another RSPLD setup as illustrated in Fig. 19. The central axis of each target is fixed, the targets are rotating on these axes, and a laser beam is scanned from a target to a target. By this method the deposition cycle period can be as short as $15 \mathrm{~ms}(70 \mathrm{~Hz})$ using the maximum repetition rate of our ArF laser $(200 \mathrm{~Hz})$, which should yield ten times faster deposition than the present setup.

Recently a new version of PLD: off-axis PLD was proposed, ${ }^{35}$ which was reported to substantially eliminate particulates in YBCO films. Its simplicity is attractive; however, in principle it works only at high ambient pressures and has difficulty in supplying cxcited species to the substrate. Contrarily, these problems do not exist in RSPLD.

\section{CONCLUSION}

We have shown the thickness distribution of elements of films deposited at relatively low laser fluences in vacuum. The distributions were partly different from previous experimental and numerical results. The observed distributions could be explained if decomposition or compositional change occurred on the target surface, which was also suggested directly by chemical analyses. Therefore, use of a single target in a conventional PLD could be regarded as similar to the use of a microscopic mosaic target on a single target holder.

Based on this conclusion, we took a new PLD approach to use multitargets: RSPLD. The deposition cycle in RSPLD was only a few orders of magnitude shorter than conventional layer-by-layer sequential deposition methods, which may not be guaranteed to suppress growth of secondary phases. Moreover, the deposition was performed in a high molecular oxygen pressure of $\sim 100$ mTorr, while most of the previous layer-by-layer sequential depositions was carried out in an ozone or oxygen radical atmosphere at a low ambient pressure of $\sim 10^{5}$ Torr. Despite these possible deficiencics, a reactive RSPLD could avoid precipitate growth and achieve high crystallographic and electrical properties, both of which have not been accomplished in conventional layer-by-layer sequential depositions. More important, a reactive RSPLD could substantially eliminate particulate formation on $\mathrm{YBa}_{2} \mathrm{Cu}_{3} \mathrm{O}_{7}$ films which typically had a $T_{c}$ of 80 $\mathrm{K}$ and a maximum $T_{c}$ of $90 \mathrm{~K}$. Additionally, the present result demonstrated successful YBCO depositions by a reactive PLD using metal targets. Essential points of present approach are the use of separate multiple metal targets and quasicodeposition. Therefore, it is also expected that a real pulsed laser codeposition should yield similar or better results. Additionally, use of low laser power density may be also beneficial to future employment of diode lasers in RSPLD or laser codeposition.

\section{ACKNOWLEDGMENTS}

Y.W. acknowledges Masanobu Ishida for the aid in the simulation of the thermal profile, Y. Seki for alloy target formation, and Dr. S. Uchida for precious encouragements.

${ }^{1}$ J. T. Cheung and H. Sankur, CRC Crit. Rev. Solid State Mater. Sci. 15, 63 (1988); J. T. Cheung and J. Horwitz, MRS Bull. February, 30 (1992).

${ }^{2}$ For an example, see D. B. Chrisey and A. Inam, MRS Bull. February, 37 (1992); T. Venkatesan, X. D. Wu, R. Muenchausen, and A. Pique, ibid. February, 54 (1992).

${ }^{3}$ H. Karl and B. Stritzker, Phys. Rev. Lett. 69, 2939 (1992).

${ }^{4}$ For example, see D. Lubben, S. Barnett, K. Suzuki, S. Gorbatikin, and J. Green, J. Vac. Sci. Technol, B 3, 968 (1985); J. T. Cheung, G. Niizawa, J. Moyle, N. P. Ong, B. M. Paine, and T. Vreeland, Jr., J. Vac. Sci, Technol. A 4, 2086 (1986).

${ }^{5}$ For example, see C. M. Cotell and K. S. Grabowski, MRS Bull. February, 44 (1992).

${ }^{6}$ For example, see O. Eibl and B. Roas, J. Mater. Res. 5, 2620 (1990).

${ }^{7}$ D. Roy, C. J. Peng, and S. B. Krupanidhi, Appl. Phys. Lett. 60, 2478 (1992).

${ }^{8}$ F. Sanchez, M. Varela, X. Queralt, R. Aguiar, and J. L. Morenza, Appl. Phys. Lett. 61, 2228 (1992).

${ }^{9}$ Y. Watanabe, Y. Matsumoto, H. Kunitomo, M. Tanamura, and E. Nishimoto, Jpn. J. Appl. Phys. 33, 5182 (1994).

${ }^{10}$ R. Ramesh, A. Inam, D. M. Hwang, T. D. Sands, C. C. Chang, and D. L. 
Hart, Appl. Phys. Lett. 58, 1557 (1991); C. C. Chang, X. D. Wu, R. Ramesh, X. X. Xi, T. S. Ravi, T. Venkatesan, D. M. Hwang, R. E. Munchausen, S. R. Foltyn, and S. Nogar, ibid. 57, 1814 (1990).

"G. Koren, A. Gupta, R. Baseman, M. Latwyche, and R. Laibowitz, Appl. Phys. Lett. 55, 2450 (1989).

${ }^{12}$ Y. Watanabe, Appl. Phys. Lett. 64, 1295 (1994); in Abstract of Applied Superconductivity Conference MOA-2 Chicago, 1992; Y. Watanabe, M. Tanamura, H. Asami, Y. Matsumoto, Y. Seki, and S. Matsumoto, Physica C 235-240, 579 (1994).

${ }^{13} \mathrm{H}$. Asami and Y. Watanabe, Jpn. J. Appl. Phys. 33, L1073 (1994).

${ }^{14}$ Y. Watanabe, M. Tanamura, S. Matsumoto, and Y. Seki, J. Appl. Phys. 78, 2029 (1995).

${ }^{15}$ T. Venkatesan, X. D. Wu, A. Inam, and J. B. Wachtman, Appl. Phys. Lett. 52. 1193 (1988).

${ }^{16}$ R. E. Muenchausen, K. M. Hubbard, S. Foltyn, R. C. Estler, N. S. Nagar, and C. Jenkins, Appl. Phys. Lett. 56, 578 (1990).

${ }^{17}$ K. L. Saenger, J. Appl. Phys. 70, 5629 (1991).

${ }^{18}$ R. K. Singh and J. Narayan, Phys. Rev. B 41, 8843 (1990).

${ }^{19}$ D. Bhattacharya, R. K. Singh, and P. H. Holloway, J. Appl. Phys. 70, 5433 (1991).

${ }^{20}$ S. R. Foltyn, R. C. Dye, K. C. Ou, E. Peterson, K. M. Hubbard, W. Hutchinson, R. E. Muenchausen, R. C. Ester, and X. D. Wu, Appl. Phys. Lett. 59, 594 (1991).

${ }^{21}$ K. H. Young, Physica C 211, I (1993); A. Cohen, P. Allenspacher, M. M. Brieger, I. Jeuck, and H. Opower, Appl. Phys. Lett. 59, 2186 (1991).

${ }^{22} \mathrm{~K}$. Matsumoto, T. Nakamura, and Y. Watanabe, Mitsubishi Kasei R\&D Rev. 7, 1 (1993) (in Japanese).

${ }^{23}$ R. S. Roth, K. L. Davis, and J. R. Dennis, Adv. Ceram. Mater. 2, 303
(1987); B. T. Ahn, V. Y. Lee, R. Beyers, T. M. Gur, and R. A. Huggins, Physica C 167, 529 (1990).

${ }^{24}$ J. P. Zheng, Z. Q. Huang, D. T. Shaw, and H. S. Kwok, Appl. Phys. Lett. 54, 280 (1989).

${ }^{25}$ P. E. Dyer, A. Issa, and P. H. Key, Appl. Phys. Lett. 57, 186 (1990)

${ }^{26}$ C. Girault, D. Damiani, C. Champeaux, P. Marchet, J. P. Mercurio, J. Aubreton, and A. Catherinot, Appl. Phys. Lett. 56, 1472 (1990).

${ }^{27}$ S. K. Hau, K. H. Wong, P. W. Chan, and C. L. Choy, Appl. Phys. Lett. 66, 245 (1995).

${ }^{28}$ T. Okada, Y. Nakayama, W. K. A. Kumuduni, and M. Maeda, Appl. Phys. Lett. 61, 2368 (1992)

${ }^{29}$ M. Kanai, T. Kawai, and S. Kawai, Appl. Phys. Lett. 58, 771 (1991).

${ }^{30}$ A. Tukamoto, J. Amano, K. I. Imagawa, and K. Kanehori, in Extended Abstracts of the 9th International Workshop on Future Electron Devices, FED-102 (Research \& Development Association for Future Electron Devices, Tokyo, 1991), p. 76.

${ }^{31}$ A. Shuhl, R. Cabanel, S. Lequien, B. Ghyselen, S. Tyc, and C. Creuzet, Appl. Phys. Lett. 57, 819 (1990).

${ }^{32}$ K. Norimoto, R. Sekine, M. Mori, T. Harada, M. Kubo, and M. Kawai, Appl. Phys. Lett. 61, 1971 (1992).

${ }^{33}$ K. Yang, M. Dilorio, S. Yoshizumi, M. Maung, J. Zhang, P. Tsai, and M. Maple, Appl. Phys. Lett. 61, 2826 (1992).

${ }^{34} Z$. Hiroi, M. Takano, M. Azuma, Y. Takeda, and Y. Bando, Physica C 185 , 523 (1991); T. Siegrist, S. M. Zahurak, D. W. Murphy, and R. S. Roth, Nature 334, 231 (1988).

${ }^{35}$ B. Holzapfel, B. Roas, L. Schultz, P. Bauer, and G. S-Ischenko, Appl. Phys. Lett. 61, 3178 (1992). 